\title{
Apparent diffusion coefficient cannot discriminate metastatic and non-metastatic lymph nodes in rectal cancer: a meta-analysis
}

\author{
Alexey Surov ${ }^{1}\left[\right.$ [D $\cdot$ Hans-Jonas Meyer ${ }^{2}$ (i) $\cdot$ Maciej Pech ${ }^{1} \cdot$ Maciej Powerski ${ }^{1} \cdot J_{a s a n}$ Omari ${ }^{1} \cdot$ Andreas Wienke $^{3}$
}

Accepted: 16 June 2021 / Published online: 29 June 2021

(c) The Author(s) 2021

\begin{abstract}
Background Our aim was to provide data regarding use of diffusion-weighted imaging (DWI) for distinguishing metastatic and non-metastatic lymph nodes (LN) in rectal cancer.

Methods MEDLINE library, EMBASE, and SCOPUS database were screened for associations between DWI and metastatic and non-metastatic LN in rectal cancer up to February 2021. Overall, 9 studies were included into the analysis. Number, mean value, and standard deviation of DWI parameters including apparent diffusion coefficient (ADC) values of metastatic and non-metastatic LN were extracted from the literature. The methodological quality of the studies was investigated according to the QUADAS-2 assessment. The meta-analysis was undertaken by using RevMan 5.3 software. DerSimonian, and Laird random-effects models with inverse-variance weights were used to account the heterogeneity between the studies. Mean DWI values including 95\% confidence intervals were calculated for metastatic and non-metastatic LN.

Results ADC values were reported for $1376 \mathrm{LN}, 623$ (45.3\%) metastatic LN, and 754 (54.7\%) non-metastatic LN. The calculated mean $\mathrm{ADC}$ value $\left(\times 10^{-3} \mathrm{~mm}^{2} / \mathrm{s}\right)$ of metastatic $\mathrm{LN}$ was $1.05,95 \% \mathrm{CI}(0.94,1.15)$. The calculated mean ADC value of the non-metastatic LN was $1.17,95 \% \mathrm{CI}(1.01,1.33)$. The calculated sensitivity and specificity were $0.81,95 \% \mathrm{CI}(0.74$, $0.89)$ and $0.67,95 \% \mathrm{CI}(0.54,0.79)$.
\end{abstract}

Conclusion No reliable ADC threshold can be recommended for distinguishing of metastatic and non-metastatic LN in rectal cancer.

Keywords Rectal cancer $\cdot$ DWI $\cdot$ ADC $\cdot$ Lymph node

\section{Introduction}

Rectal cancer (RC) is the second most commonly diagnosed cancer among both men and women in the USA with more than 40,000 cases per year [1]. The presence of nodal metastases is one of the most important prognostic factors in rectal cancer. So far, it has been shown that patients with $\mathrm{pN} 2$ nodal involvement have worse survival $[2,3]$. Therefore, the presence of lymph node metastases is acknowledged to predict overall

Alexey Surov

Alexey.Surov@med.ovgu.de

1 Department of Radiology and Nuclear Medicine, Otto-vonGuericke University Magdeburg, Magdeburg, Germany

2 Department of Diagnostic and Interventional Radiology, University of Leipzig, Leipzig, Germany

3 Institute of Medical Epidemiology, Martin-Luther-University Halle-Wittenberg, Biostatistics, and Informatics, Halle (Saale), Germany survival (OS) and disease-free survival (DFS) in non-metastatic $\mathrm{RC}[2,3]$. Moreover, lymph nodal status is an essential factor in determining the need for adjuvant chemotherapy after surgical resection $[2,3]$. Therefore, early and correct diagnosis of lymph node metastasis should improve assessment of the tumor stage and facilitate selection of the most appropriate treatment.

For staging purposes, magnetic resonance imaging (MRI) plays an essential diagnostic role in RC [4]. MRI has a high accuracy for tumoral (T) staging in RC [4]. However, for LN staging, the role of MRI is limited due to several concerns $[5,6]$. It is related to the fact that classical morphological features like shape, size, signal intensity, and enhancement of contrast medium cannot reliably discriminate metastatic and non-metastatic LN. In fact, previous studies showed that the diameter of benign and malignant nodes in RC was similar, which leads to a low accuracy $[5,6]$. Other morphological criteria, such as signal intensity, board margin, and enhancement intensity, did not improve significantly the diagnostic accuracy of metastatic LN in RC [6]. 
Some reports showed that diffusion weighted imaging (DWI) has a great diagnostic potential and can better characterize tumors than conventional MRI [7]. DWI is a magnetic resonance imaging (MRI) sequence based on the quantification of water motion in tissues which can be expressed by apparent diffusion coefficient (ADC) [7]. It has been widely shown that ADC is inversely associated with cell count and proliferation potential throughout oncology [7-9]. A key fact is that typically malignant tumors have lower ADC values in comparison to benign ones, which was shown for several body regions [10-12].

Presumably, due to the association with cellularity and microvasculature, DWI may be helpful to distinguish metastatic from non-metastatic $\mathrm{LN}$ as it could reflect distinctive histopathology differences between these.

However, there is still lack of reliable data regarding the accuracy of DWI to predict nodal status in RC.

Therefore, the purpose of the present meta-analysis was to evaluate diagnostic utility of DWI/ADC parameters for distinguishing metastatic and non-metastatic lymph nodes in RC.

\section{Methods}

\section{Data acquisition}

MEDLINE library and SCOPUS database were screened for associations between ADC and $\mathrm{LN}$ status in patients with RC up to February 2021. The following search terms/combinations were used as follows:

"DWI or diffusion weighted imaging or diffusionweighted imaging or ADC or apparent diffusion coefficient AND rectal cancer OR rectal carcinoma OR rectum cancer OR rectum carcinoma AND lymph node OR lymph node metastases OR lymph node metastasis." Secondary references were also manually checked and recruited. The Preferred Reporting Items for Systematic Reviews and MetaAnalyses statement (PRISMA) was used for the research [13].

The primary search identified 215 records (Fig. 1). The abstracts of the items were checked. Inclusion criteria for this meta-analysis were as follows:
Fig. 1 PRISMA flow chart of the data acquisition. Overall, 9 studies comprising with 1376 lymph nodes were included into the present study
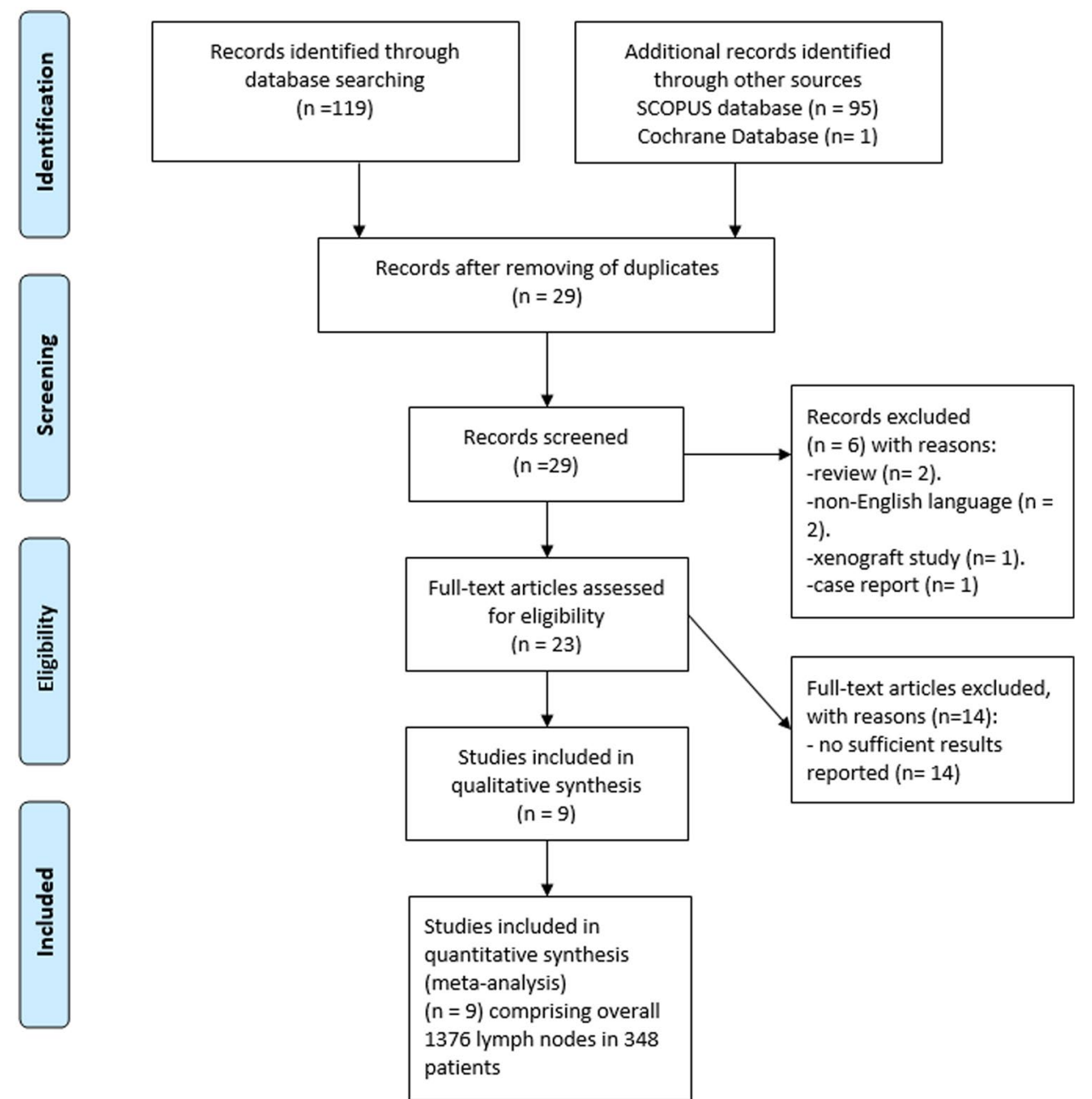


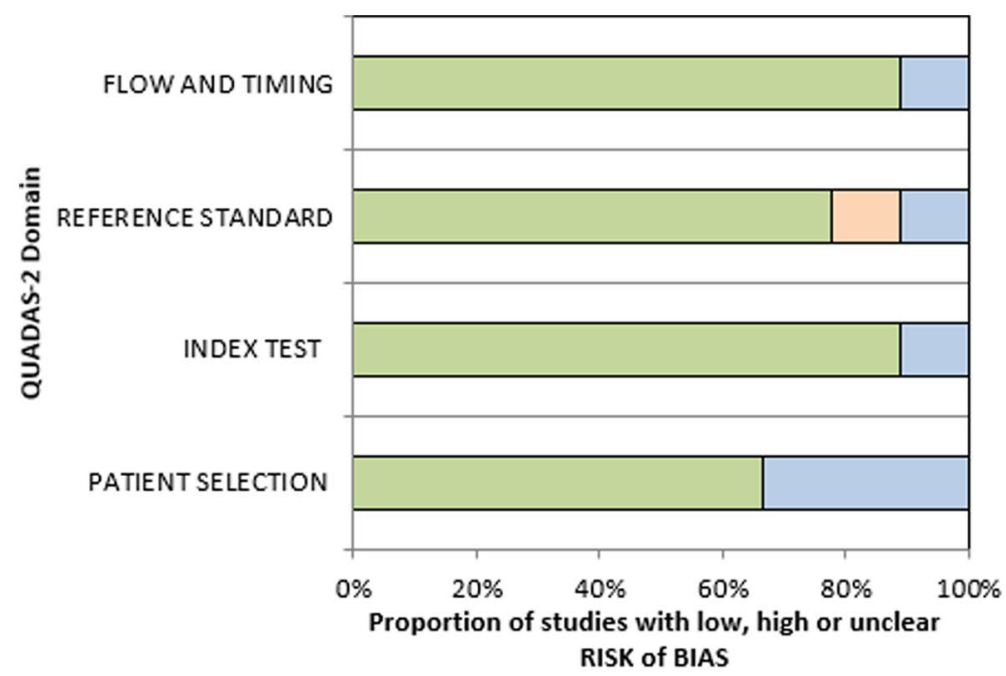

$\square$ Low $\square$ High $\square$ Unclear

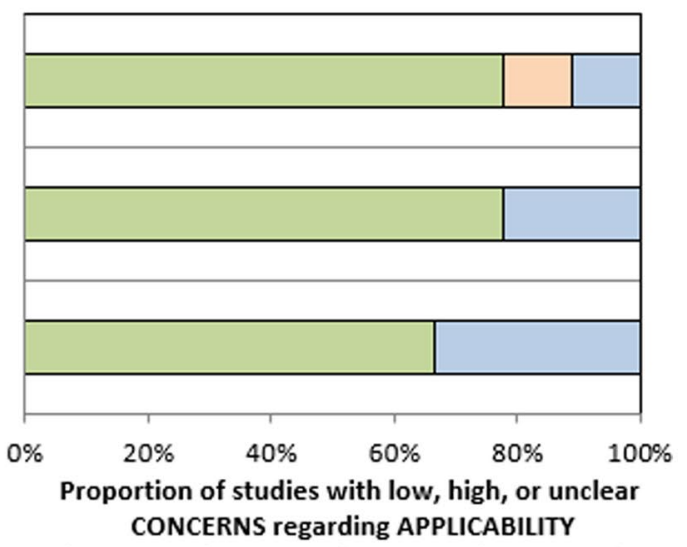

Fig. 2 QUADAS-2 quality assessment of the included studies. Most studies showed overall a low risk for bias

- data derived from diffusion weighted imaging (DWI);

- available mean and standard deviation values of ADC;

- original studies investigated humans;

Exclusion criteria were as follows:

- studies unrelated to the research subjects;

- studies with incomplete data;

- duplicate publications;

- experimental animals and in vitro studies;

- review, meta-analysis and case report articles;

After thoroughly review, 9 items met the inclusion criteria and were included into the present analysis [14-22].

The following data were extracted from the literature: authors, year of publication, study design, number of patients, number of analyzed lymph nodes, mean value, and standard deviation of DWI parameters.

\section{Meta-analysis}

On the first step, the methodological quality of the included 9 studies was checked according to the Quality Assessment of Diagnostic Studies (QUADAS-2) instrument [23] by one observer (H.J.M) (Fig. 2). On the second step, the reported DWI values (mean and standard deviation) were acquired. On the third step, the meta-analysis was undertaken by using RevMan 5.3 (RevMan 2014. The Cochrane Collaboration Review Manager Version 5.3.) [24, 25]. Heterogeneity was calculated by means of the inconsistency index $\mathrm{I}^{2}$. The interpretation of $\mathrm{I}^{2}$ was the following: 0 to $40 \%$ : not important, 30 to $60 \%$ : moderate heterogeneity, 50 to $90 \%$ : substantial heterogeneity, and 75 to $100 \%$ : considerable heterogeneity as defined by the Cochrane institute [26]. Then, DerSimonian and Laird random-effects models with inverse-variance weights were used without any further correction to account for the heterogeneity between the studies [27]. Mean values including 95\% confidence intervals were calculated separately for metastatic and non-metastatic LN.
Table 1 Data regarding included studies

\begin{tabular}{llllll}
\hline Authors & Study design & Patients & $\begin{array}{l}\text { Investigated } \\
\text { LN, total }\end{array}$ & Metastatic LN, n (\%) & Reference standard \\
\hline Cerny et al. [14] & Prospective & 27 & 63 & $44(69.8)$ & PET \\
Cho et al. [15] & Retrospective & 34 & 114 & $46(40.4)$ & Histopathology \\
Ge et al. [17] & Prospective & 46 & 67 & $43(64.2)$ & Histopathology \\
Heijnen et al. [16] & Retrospective & 21 & 102 & $12(11.8)$ & Histopathology \\
Li et al. [18] & Unclear & 21 & 284 & $168(59.2)$ & Histopathology \\
Qui et al. [19] & Prospective & 68 & 160 & $93(58.1)$ & Histopathology \\
Yasui et al. [20] & Prospective & 46 & 162 & $76(46.1)$ & Histopathology \\
Yu et al. [21] & Prospective & 50 & 59 & $31(52.5)$ & Histopathology \\
Zhuang et al. [22] & Unclear & 35 & 115 & $65(56.5)$ & Histopathology \\
\hline
\end{tabular}

$L N$ lymph nodes 
Table 2 Data about the involved patients and treatments

\begin{tabular}{ll}
\hline Patients & $\mathrm{n}(\%)$ \\
\hline Total & 348 \\
Female & $166(43.3)$ \\
Male & $217(46.7)$ \\
Age & \\
25-88 years & \\
Treatment & $\mathrm{n}(\%)$ \\
Surgery & $318(83.0)$ \\
Neoadjuvant ther- & $44(11.5)$ \\
$\quad$ apy and surgery & \\
Not reported & $21(5.5)$ \\
\hline
\end{tabular}

\section{Results}

Of the included 9 studies, 2 were retrospective (22.2\%), 5 prospective (55.6\%), and in 2 studies $(22.2 \%)$; the design was unclear (Table 1). Data regarding technical details of MR investigations are given in Table 2.

\section{Risk of bias}

Patient selection was generally well defined within the respective methodology; yet, 4 studies (44.4\%) did not report the inclusion and exclusion criteria clearly which can account for potential bias.

All studies clearly reported methodology of the index test and were accordingly not considered a significant source of potential bias.

Eight studies (88.9\%) utilized histopathology evaluations as reference test. Only one study can be considered as a risk of bias which used PET-CT as reference standard [14].
The acquired 9 studies comprised 348 patients with RC. Demographic data of the patients are shown in Table 3. In these patients, $1376 \mathrm{LN}$ were analyzed. There were 623 (45.3\%) metastatic LN and 754 (54.7\%) non-metastatic LN.

\section{ADC values of $L N$}

ADC values were reported for $1376 \mathrm{LN}, 623(45.3 \%)$ metastatic LN, and 754 (54.7\%) non-metastatic LN. The calculated mean ADC value $\left(\times 10^{-3} \mathrm{~mm}^{2} / \mathrm{s}\right)$ of metastatic LN was $1.05,95 \% \mathrm{CI}(0.94,1.15)$. The calculated mean ADC value of the non-metastatic LN was $1.17,95 \% \mathrm{CI}$ (1.01, 1.33) (Fig. 3a). The graphical distribution of ADC values of metastatic and non-metastatic $\mathrm{LN}$ is shown in Fig. 3b.

\section{Tesla strength}

A subgroup analysis was performed to divide the studies according to tesla strength.

Four studies utilized a $1.5 \mathrm{~T}$ scanner comprising $441 \mathrm{LN}$, 178 metastatic LN (40.3\%), and 264 non-metastatic LN $(59.7 \%)$. The calculated mean ADC value $\left(\times 10^{-3} \mathrm{~mm}^{2} / \mathrm{s}\right)$ of metastatic LN was $1.09,95 \%$ CI $(0.91,1.28)$. The calculated mean ADC value of the non-metastatic LN was 1.37, 95\% CI (1.09, 1.64) (Fig. 4).

Five studies utilized a $3 \mathrm{~T}$ scanner comprising $935 \mathrm{LN}$, 445 metastatic LN (47.6\%), and 490 non-metastatic LN $(52.4 \%)$. The calculated mean ADC value $\left(\times 10^{-3} \mathrm{~mm}^{2} / \mathrm{s}\right)$ of metastatic LN was $1.01,95 \% \mathrm{CI}(0.86,1.16)$. The calculated mean $\mathrm{ADC}$ value of the non-metastatic $\mathrm{LN}$ was 1.02, 95\% CI (0.83, 1.22) (Fig. 4).

Table 3 Technical details of MR investigations

\begin{tabular}{|c|c|c|c|c|c|}
\hline Authors & MR scanner & $\mathrm{b}$ values, $\mathrm{s} / \mathrm{mm}^{2}$ & $\mathrm{TR} / \mathrm{TE}, \mathrm{ms}$ & FoV, mm & Slice thickness, mm \\
\hline Cerny et al. [14] & $\begin{array}{l}\text { 1.5 T Magnetom Aera; Siemens } \\
\text { Healthcare }\end{array}$ & 0,600 & $3200 / 55$ & $350 \times 563$ & 5 \\
\hline Cho et al. [15] & $\begin{array}{l}\text { 1.5 T Signa Excite; GE Medical } \\
\text { Systems }\end{array}$ & 0,1000 & $8000 / 85.2$ & $300 \times 300$ & 5 \\
\hline Ge et al. [17] & 3 T 750 W GE Medical Systems & 0,800 & $3648 / 70$ & $360 \times 360$ & 5 \\
\hline Heijnen et al. [16] & $\begin{array}{l}\text { 1.5 T Intera or Intera } \\
\text { Achieva; Philips Medical Systems }\end{array}$ & $0,500,1000$ & $4829 / 70$ & n.r & n.r \\
\hline Li et al. [18] & $\begin{array}{l}\text { Different } 3 \text { T scanners of GE Medi- } \\
\text { cal Systems }\end{array}$ & $\begin{array}{c}0,50,100,150,200,300,500,800 \\
1000,1300,1500,1700,2000\end{array}$ & 2600/minimum & $320 \times 320$ & 5 \\
\hline Qui et al. [19] & $\begin{array}{l}3 \text { T Discovery 750, GE Medical } \\
\text { Systems }\end{array}$ & $\begin{array}{l}0,25,50,75,100,150,200,400 \\
\quad 600,800,1000,1200,1500,2000\end{array}$ & 2200/minimum & $260 \times 260$ & 4 \\
\hline Yasui et al. [20] & $\begin{array}{l}1.5 \text { T Intera Philips Medical } \\
\text { Systems }\end{array}$ & 0,800 & $3704 / 68$ & $375 \times 375$ & 8 \\
\hline Yu et al. [21] & $\begin{array}{l}\text { 1.5 T Optima MR360, GE Health- } \\
\text { care }\end{array}$ & $\begin{array}{l}0,10,20,30,50,80,100,150,200 \\
\quad 400,600,800\end{array}$ & $4500 / 97$ & $380 \times 300$ & 3 \\
\hline Zhuang et al. [22] & $3 \mathrm{~T}$ & Unclear & Unclear & Unclear & Unclear \\
\hline
\end{tabular}

n.r. not reported 
Fig. 3 a Forest plots of ADC values reported for metastatic and non-metastatic lymph nodes. The calculated mean ADC value $\left(\times 10^{-3} \mathrm{~mm}^{2} / \mathrm{s}\right)$ of metastatic LN was $1.05,95 \% \mathrm{CI}$ $(0.94,1.15)$. The calculated mean ADC value of the non-metastatic $\mathrm{LN}$ was 1.17 , 95\% CI (1.01, 1.33). b Graphical distribution of ADC values of metastatic and non-metastatic lymph nodes. The box plots overlap significantly, that no clear threshold ADC-value can be recommended

\section{Discrimination analysis}

Furthermore, in 7 studies, ADC thresholds discriminating metastatic from non-metastatic $\mathrm{LN}$ and data of ROC analysis were reported (Table 4, Fig. 5).

The calculated sensitivity and specificity were $0.81,95 \% \mathrm{CI}$ $(0.74,0.89)$ and $0.67,95 \% \mathrm{CI}(0.54,0.79)$, respectively (Fig. 5).
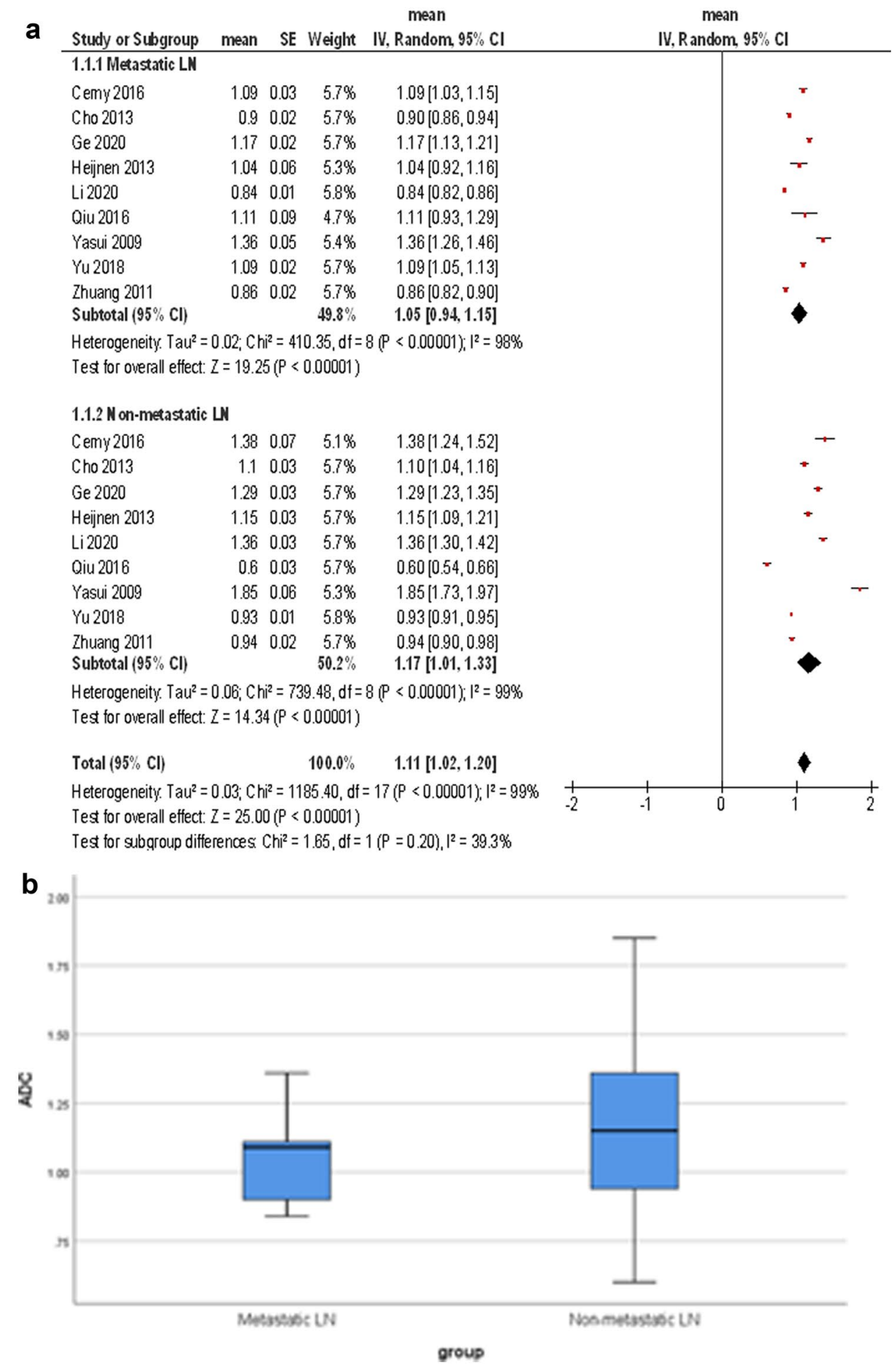

\section{Discussion}

The present analysis addressed the important clinical question, whether DWI can aid to diagnose the correct nodal status in RC. This is of interest as on the one hand LN status plays a great prognostic role. On the other hand, conventional MRI cannot definitively discriminate metastatic and non-metastatic LN. 
Fig. 4 Forest plots of ADC values reported for metastatic and non-metastatic lymph nodes according to tesla strength. For 1.5 $\mathrm{T}$ scanners, the calculated mean ADC value $\left(\times 10^{-3}\right.$ $\mathrm{mm}^{2} / \mathrm{s}$ ) of metastatic $\mathrm{LN}$ was $1.09,95 \% \mathrm{CI}(0.91,1.28)$, and of the non-metastatic $\mathrm{LN}$, it was $1.37,95 \% \mathrm{CI}(1.09,1.64)$. For $3 \mathrm{~T}$ scanners, the ADC value of metastatic $\mathrm{LN}$ was $1.01,95 \% \mathrm{CI}(0.86,1.16)$, and for non-metastatic $\mathrm{LN}$, it was $1.02,95 \% \mathrm{CI}(0.83,1.22)$

\section{ADC Tesla 1.5}

\begin{tabular}{lrrrr|r} 
Study or Subgroup & mean & SE Weight & $\begin{array}{c}\text { mean } \\
\text { IV, Random, 95\% Cl }\end{array}$ & mean \\
IV, Random, 95\% Cl
\end{tabular}

Test for subaroup differences: $\mathrm{Ch}^{2}=2.57, \mathrm{df}=1(\mathrm{P}=0.11) . \mathrm{I}^{2}=61.0 \%$

ADC Tesla 3

mean mean

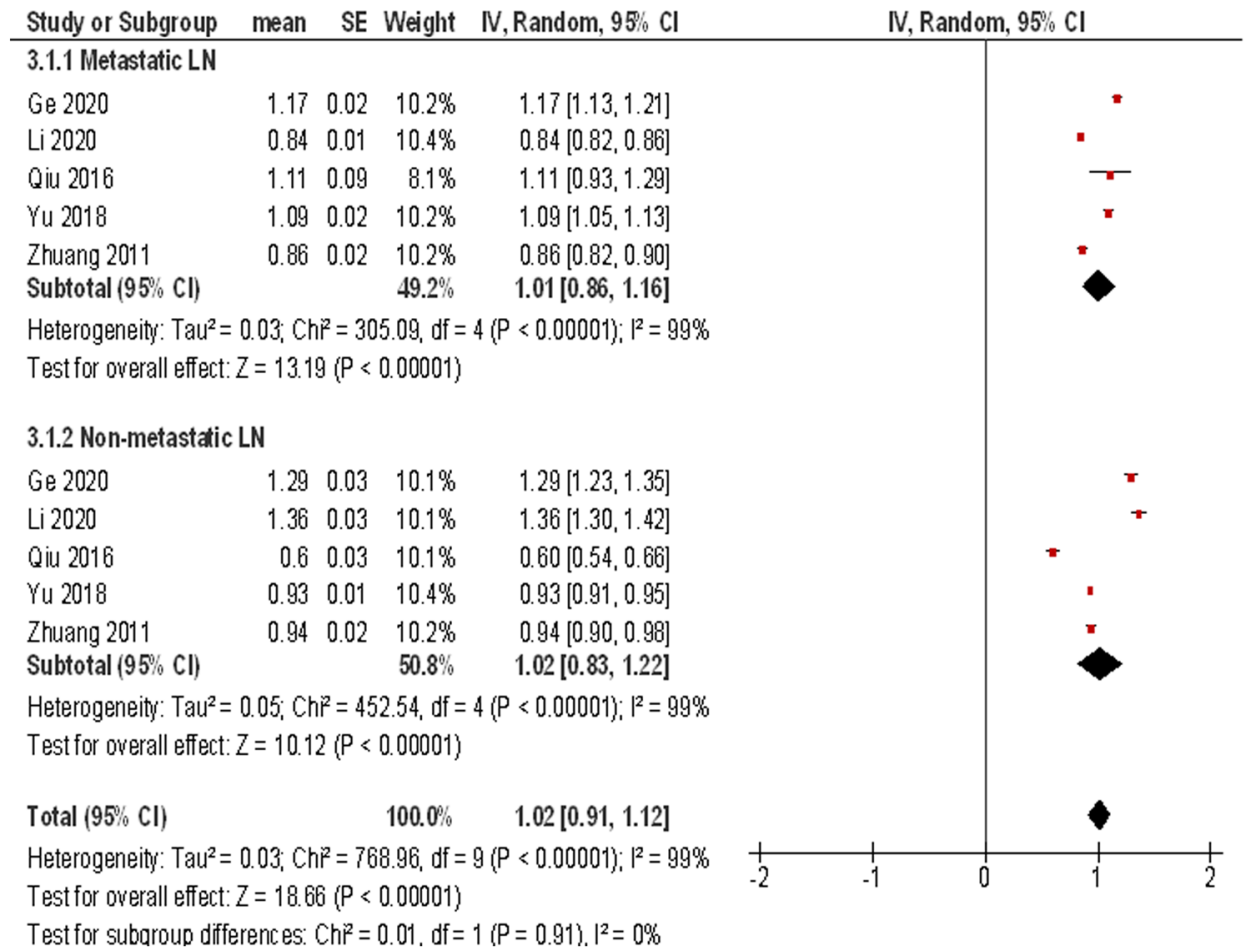

It is well known that lymph node metastases in RC occur usually along the mesorectal nodal chain of the inferior mesenteric artery, or in the lateral pelvic sidewall nodes, which include the internal iliac, obturator and medial external iliac chains [28, 29]. Interestingly, lateral pelvic lymph node metastases occur in 10-25\% of patients with RC and are associated with higher local recurrence and reduced survival rates [28]. On the other hand, there is a significant risk of urinary and sexual dysfunction after surgical dissection of lateral pelvic lymph nodes [28, 29]. Therefore, recent studies 
Table 4 Optimal cutoffs, sensitivity, and specificity for ADC values

\begin{tabular}{llll}
\hline Autors & $\begin{array}{l}\text { Cutoff ADC- } \\
\text { values }\end{array}$ & Sensitivity & Specificity \\
\hline Cho et al. [15] & 1.00 & 0.78 & 0.67 \\
Heijnen et al. [16] & 1.07 & 0.67 & 0.60 \\
Li et al. [18] & 1.01 & 0.89 & 0.78 \\
Qui et al. [19] & 0.80 & 0.87 & 0.88 \\
Yasui et al. [20] & 1.44 & 0.75 & 0.74 \\
Yu et al. [21] & 0.98 & 0.65 & 0.67 \\
Zhuang et al. [22] & 1.05 & 0.93 & 0.30 \\
\hline
\end{tabular}

indicated that a greater accuracy in preoperative staging is needed to select those patients that will benefit from lateral lymph node dissection surgery [29, 30].

These facts underline the need for imaging modalities and/ or parameters, which can better identify LN metastases in RC.

As reported previously, besides diagnostic value, DWI can provide additional information regarding tissue microstructure [7-10]. One key finding is that ADC correlated inversely with cell count in different tumors [8]. Furthermore, ADC correlated also inversely with proliferation index Ki-67 indicating to reflect tumor biology [9]. So far, in ovarian cancer, cerebral lymphomas, and urothelial carcinoma, the pooled correlation coefficients between mean $\mathrm{ADC}$ and expression of $\mathrm{Ki}-67$ were $-0.62,-0.56$, and -0.55 , respectively [9]. In meningioma, ADC can differentiate low and high-grade tumors [31]. In prostate cancer, ADC is inversely associated with Gleason score and can be helpful to predict high-risk tumors [32].

DWI also reflects different histopathological features in RC. In the study of Ao et al., ADC correlated well with $\mathrm{Ki}-67(\mathrm{r}=-0.71, \mathrm{p}<0.01)$ [33]. Meng et al. showed that ADC correlated with expression of VEGF and HIF 1a [34].

Importantly, ADC can also distinguish malignant and benign lesions in different organs. For instance, in the head and neck region, it has been shown that ADC values $\leq 0.65 \times 10^{-3} \mathrm{~mm}^{2} / \mathrm{s}$ had a positive predictive value of malignancy of $100 \%$ and ADC values $\leq 1.01 \times 10^{-3} \mathrm{~mm}^{2} / \mathrm{s}$ had a positive predictive value of malignancy of $90 \%$ [35]. Furthermore, different breast cancers have typically ADC values lower than 1.00 , whereas benign breast lesions have ADC values higher than $1.0 \times 10^{-3} \mathrm{~mm}^{2} / \mathrm{s}$ [36]. Similar results were reported for renal lesions [37].

Previously, DWI parameters were also utilized for discrimination of benign $\mathrm{LN}$ from LN metastases throughout oncology. For example, Xing et al. showed that ADC value of metastatic $\mathrm{LN}$ was lower than non-metastatic $\mathrm{LN}$ in breast cancer with the high pooled sensitivity $(0.86)$, specificity (0.86), PPV (0.82), and NPV (0.90) [38]. Similar results were also reported for ADC values in cervical LN [39].

In $\mathrm{RC}$, the reported data were inconsistent. While some authors found that ADC could discriminate metastatic
Fig. 5 Forest plots of sensitivity (a) and specificity (b) of $\mathrm{ADC}$ values for distinguishing between metastatic and non-metastatic lymph nodes. The calculated sensitivity and specificity were $0.81,95 \% \mathrm{CI}$ $(0.74,0.89)$ and $0.67,95 \% \mathrm{CI}$ $(0.54,0.79)$, respectively

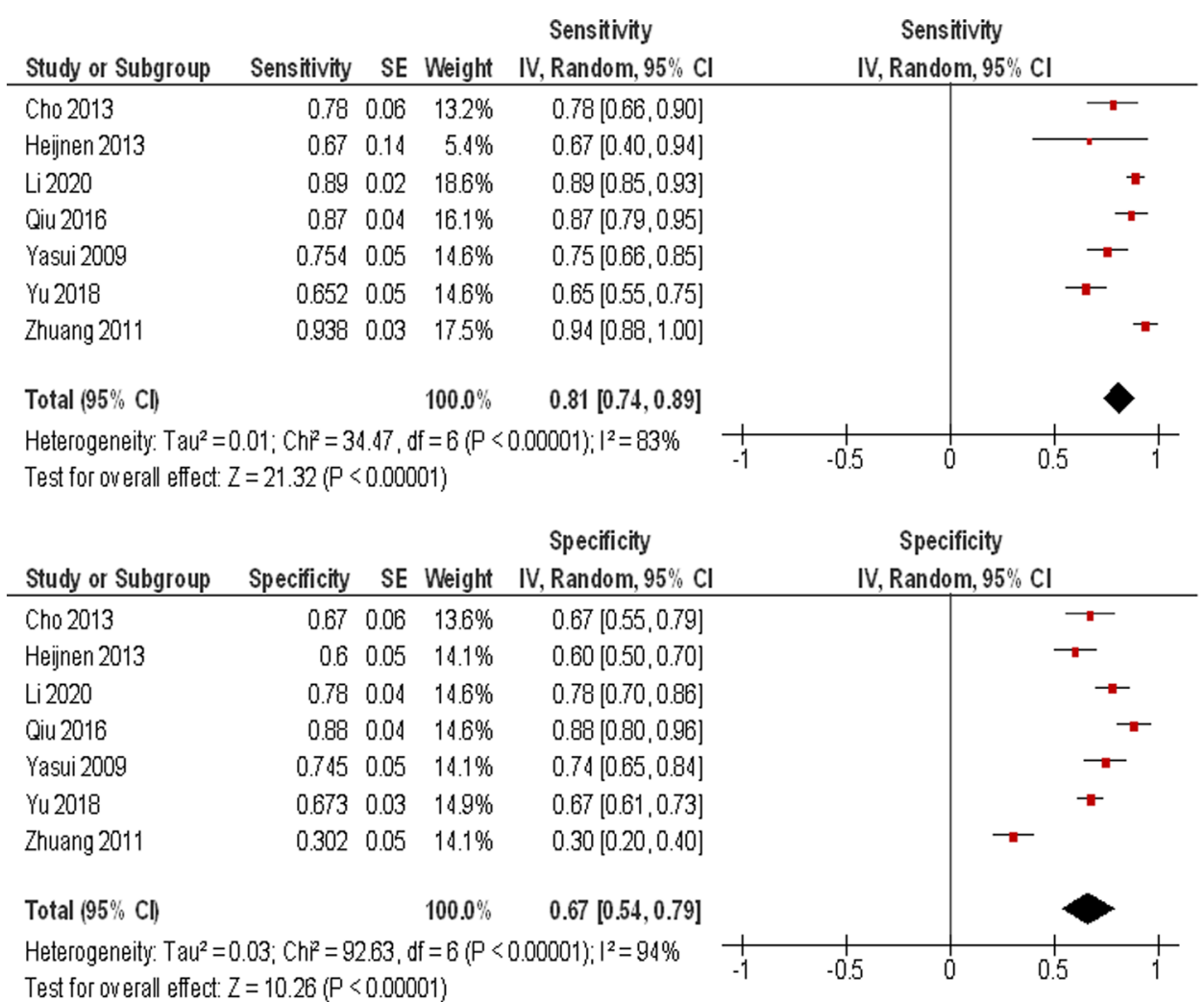


and non-metastatic $\mathrm{LN}$ in RC, others did not. For example, Cerny et al. found that mean ADC values of pathological LN were significantly lower than in control LN $(p=0.0012)$ [14]. Similar results were also reported by Heijnen et al. [16]. However, in the investigation of Qiu et al., metastatic LN showed higher ADC values $(1.11 \pm 0.89)$ in comparison to non-metastatic $\mathrm{LN}$ $(0.6 \pm 0.21), \mathrm{p}<0.01[19]$.

Furthermore, the reported studies analyzed a relatively small number of patients and lymph nodes. These facts underline the need for evident data based on a large sample.

The present analysis shows that no reliable threshold for ADC values can be recommended to predict nodal status in RC. Another important point is the high heterogeneity identified of the ADC values. This might be caused by different scanner technology, b-values of the DWI, different ADC calculations, and field strength. This is crucial to acknowledged before ADC values can be used in clinical routine as a valuable imaging biomarker.

There are some limitations of the present study. First, it is based on published results in the literature with a known publication bias. Second, only a small number of studies met the inclusion criteria for this analysis and many studies were excluded because some data; e.g., ADC mean values and/or standard deviation were missing. Third, there is the restriction to published papers in English language. Fourth, different MR techniques, i.e., scanners, sequences, and slice thickness, were used in the included studies. Finally, in the included studies, some relevant clinical data like localization of the investigated lymph nodes, tumor stage, and grading were missing and could not be analyzed. Overall, the above mentioned factors resulted in a high heterogeneity between the studies. This fact may relativize our results. However, the results of this meta-analysis are based on a large cohort and provide evident data about the current role of DWI in LN staging in RC.

In conclusion, $\mathrm{ADC}$ cannot distinguish metastatic and non-metastatic LN in rectal cancer. No reliable ADC threshold can be recommended to predict nodal status.

Author contribution Study concept and design: AW; AS; Acquisition of data: AS, AW, HJM, MP, MP, JO; Analysis and interpretation of data: AS, AW, HJM, MP, MP, JO. Statistical analysis: AW. Drafting of the manuscript: AS. Critical revision of the manuscript for important intellectual content: all authors; Approval of the final version of the manuscript: all authors.

Funding Open Access funding enabled and organized by Projekt DEAL.

\section{Declarations}

Ethics approval and consent to participate This study was approved by the ethical committees of the Medical Faculty of the University of Magdeburg.
Conflict of interest The authors declare no competing interests.

Open Access This article is licensed under a Creative Commons Attribution 4.0 International License, which permits use, sharing, adaptation, distribution and reproduction in any medium or format, as long as you give appropriate credit to the original author(s) and the source, provide a link to the Creative Commons licence, and indicate if changes were made. The images or other third party material in this article are included in the article's Creative Commons licence, unless indicated otherwise in a credit line to the material. If material is not included in the article's Creative Commons licence and your intended use is not permitted by statutory regulation or exceeds the permitted use, you will need to obtain permission directly from the copyright holder. To view a copy of this licence, visit http://creativecommons.org/licenses/by/4.0/.

\section{References}

1. Siegel RL, Miller KD, Goding Sauer A, Fedewa SA, Butterly LF, Anderson JC, Cercek A, Smith RA, Jemal A (2020) Colorectal cancer statistics. CA Cancer J Clin 70(3):145-164

2. Chang GJ, Rodriguez-Bigas MA, Skibber JM, Moyer VA (2007) Lymph node evaluation and survival after curative resection of colon cancer: systematic review. J Natl Cancer Inst 99(6):433-441

3. Karjol U, Jonnada P, Chandranath A, Cherukuru S (2020) Lymph node ratio as a prognostic marker in rectal cancer survival: a systematic review and meta-analysis. Cureus 12(5):e8047

4. Zhang G, Cai YZ, Xu GH (2016) Diagnostic accuracy of MRI for assessment of $\mathrm{T}$ category and circumferential resection margin involvement in patients with rectal cancer: a meta-analysis. Dis Colon Rectum 59(8):789-799

5. Brown G, Richards CJ, Bourne MW, Newcombe RG, Radcliffe AG, Dallimore NS, Williams GT (2003) Morphologic predictors of lymph node status in rectal cancer with use of high-spatialresolution MR imaging with histopathologic comparison. Radiology 227(2):371-377

6. Gröne J, Loch FN, Taupitz M, Schmidt C, Kreis ME (2018) Accuracy of various lymph node staging criteria in rectal cancer with magnetic resonance imaging. J Gastrointest Surg 22(1):146-153

7. Le Bihan D (2013) Apparent diffusion coefficient and beyond: what diffusion MR imaging can tell us about tissue structure. Radiology 268(2):318-322

8. Surov A, Meyer HJ, Wienke A (2017) Correlation between apparent diffusion coefficient (ADC) and cellularity is different in several tumors: a meta-analysis. Oncotarget 8(35):59492-59499

9. Surov A, Meyer HJ, Wienke A (2017) Correlation between apparent diffusion coefficient (ADC) and KI 67 in different tumors: a meta-analysis Part 1: ADCmean. Oncotarget 8(9):75434-75444

10. Padhani AR, Liu G, Koh DM, Chenevert TL, Thoeny HC, Takahara T, Dzik-Jurasz A, Ross BD, Van Cauteren M, Collins D, Hammoud DA, Rustin GJ, Taouli B, Choyke PL (2009) Diffusion-weighted magnetic resonance imaging as a cancer biomarker: consensus and recommendations. Neoplasia 11(2):102-125

11. Surov A, Meyer HJ, Wienke A (2020) Apparent diffusion coefficient for distinguishing between malignant and benign lesions in the head and neck region: a systematic review and meta-analysis. Front Oncol 9:1362

12. Penn AI, Medved M, Dialani V, Pisano ED, Cole EB, Brousseau D, Karczmar GS, Gao G, Reich BD, Abe H (2020) Discrimination of benign from malignant breast lesions in dense breasts with model-based analysis of regions-of-interest using directional diffusion-weighted images. BMC Med Imaging 20(1):61 
13. Moher D, Liberati A, Tetzlaff J, Altman DG (2009) Preferred reporting items for systematic reviews and meta-analyses: the PRISMA statement. PLoS Med 6(7):e1000097

14. Cerny M, Dunet V, Prior JO, Hahnloser D, Wagner AD, Meuli RA, Schmidt S (2016) Initial staging of locally advanced rectal cancer and regional lymph nodes: comparison of diffusion-weighted MRI with 18F-FDG-PET/CT. Clin Nucl Med 41(4):289-295

15. Cho EY, Kim SH, Yoon JH, Lee Y, Lim YJ, Kim SJ, Baek HJ, Eun CK (2013) Apparent diffusion coefficient for discriminating metastatic from non-metastatic lymph nodes in primary rectal cancer. Eur J Radiol 82(11):e662-668

16. Heijnen LA, Lambregts DM, Mondal D, Martens MH, Riedl RG, Beets GL, Beets-Tan RG (2013) Diffusion-weighted MR imaging in primary rectal cancer staging demonstrates but does not characterise lymph nodes. Eur Radiol 23(12):3354-3360

17. Ge YX, Hu SD, Wang Z, Guan RP, Zhou XY, Gao QZ, Yan G (2020) Feasibility and reproducibility of T2 mapping and DWI for identifying malignant lymph nodes in rectal cancer. Eur Radiol

18. Li F, Hu J, Jiang H, Sun Y (2019) Diagnosis of lymph node metastasis on rectal cancer by PET-CT computer imaging combined with MRI technology. J Infect Public Health S1876-0341(19):30230-30238

19. Qiu L, Liu XL, Liu SR, Weng ZP, Chen XQ, Feng YZ, Cai XR, Guo CY (2016) Role of quantitative intravoxel incoherent motion parameters in the preoperative diagnosis of nodal metastasis in patients with rectal carcinoma. J Magn Reson Imaging 44(4):1031-1039

20. Yasui O, Sato M, Kamada A (2009) Diffusion-weighted imaging in the detection of lymph node metastasis in colorectal cancer. Tohoku J Exp Med 218(3):177-183

21. Yu XP, Wen L, Hou J, Bi F, Hu P, Wang H, Wang W (2016) Discrimination between metastatic and nonmetastatic mesorectal lymph nodes in rectal cancer using intravoxel incoherent motion diffusionweighted magnetic resonance imaging. Acad Radiol 23(4):479-485

22. Zhuang XZ, Yu SP, Cui J, Chen CQ, Zhao XJ, Pan BT, Li ZP (2011) Diagnosis value of 3.0 T diffusion-weighted imaging with background suppression magnetic resonance for metastatic lymph nodes in rectal cancer. Chin J Gastrointes Surg 14(11):842-845

23. Whiting PF, Rutjes AW, Westwood ME, Mallett S, Deeks JJ, Reitsma JB, Leeflang MM, Sterne JA, Bossuyt PM (2011) QUADAS-2: a revised tool for the quality assessment of diagnostic accuracy studies. Ann Intern Med 155(8):529-536

24. Leeflang MM, Deeks JJ, Gatsonis C, Bossuyt PM (2008) Systematic reviews of diagnostic test accuracy. Ann Intern Med 149(12):889-897

25. Zamora J, Abraira V, Muriel A, Khan K, Coomarasamy A (2006) Meta-DiSc: a software for meta-analysis of test accuracy data. BMC Med Res Methodol 6:31

26. Higgins JPT, Thomas J, Chandler J, Cumpston M, Li T, Page MJ, Welch VA (editors) (2019) Cochrane handbook for systematic reviews of interventions version 6.0 (updated July 2019). Cochrane. Available from www.training.cochrane.org/handbook
27. DerSimonian R, Laird N (1986) Meta-analysis in clinical trials. Control Clin Trials 7(3):177-188

28. Georgiou P, Tan E, Gouvas N, Antoniou A, Brown G, Nicholls RJ, Tekkis P (2009) Extended lymphadenectomy versus conventional surgery for rectal cancer: a meta-analysis. Lancet Oncol 10(11):1053-1062

29. Jones HG, Radwan RW, Sams E, Gibby M, Coomer W, Jeffries J, Codd RJ, Williams GL, Taylor G, Horwood J (2020) Incidence and treatment of positive pelvic sidewall lymph nodes in patients with rectal cancer. Colorectal Dis. https://doi.org/10.1111/codi. 15176

30. Williamson JS, Quyn AJ, Sagar PM (2020) Rectal cancer lateral pelvic sidewall lymph nodes: a review of controversies and management. Br J Surg. https://doi.org/10.1002/bjs.11925

31. Surov A, Ginat DT, Sanverdi E, Lim CCT, Hakyemez B, Yogi A, Cabada T, Wienke A (2016) Use of diffusion weighted imaging in differentiating between maligant and benign meningiomas. A multicenter analysis World. Neurosurg 88:598-602

32. Meyer HJ, Wienke A, Surov A (2020) Discrimination between clinical significant and insignificant prostate cancer with apparent diffusion coefficient - a systematic review and meta analysis. BMC Cancer 20(1):482

33. Ao W, Bao X, Mao G, Yang G, Wang J, Hu J (2020) Value of apparent diffusion coefficient for assessing preoperative $\mathrm{T}$ staging of low rectal cancer and whether this is correlated with Ki-67 expression. Can Assoc Radiol J 71(1):5-11

34. Meng X, Li H, Kong L, Zhao X, Huang Z, Zhao H, Zhu W, Li X, Yu J, Xing L (2016) MRI In rectal cancer: correlations between MRI features and molecular markers Ki-67, HIF-1 $\alpha$, and VEGF. J Magn Reson Imaging 44(3):594-600

35. Wang J, Takashima S, Takayama F, Kawakami S, Saito A, Matsushita T, Momose M, Ishiyama T (2001) Head and neck lesions: characterization with diffusion-weighted echo-planar MR imaging. Radiology 220(3):621-630

36. Surov A, Meyer HJ, Wienke A (2019) Can apparent diffusion coefficient (ADC) distinguish breast cancer from benign breast findings? A meta-analysis based on 13847 lesions. BMC Cancer 19(1):955

37. Lassel EA, Rao R, Schwenke C, Schoenberg SO, Michaely HJ (2014) Diffusion-weighted imaging of focal renal lesions: a metaanalysis. Eur Radiol 24(1):241-249

38. Xing H, Song CL, Li WJ (2016) Meta analysis of lymph node metastasis of breast cancer patients: clinical value of DWI and ADC value. Eur J Radiol 85(6):1132-1137

39. Payabvash S, Brackett A, Forghani R, Malhotra A (2019) Differentiation of lymphomatous, metastatic, and non-malignant lymphadenopathy in the neck with quantitative diffusion-weighted imaging: systematic review and meta-analysis. Neuroradiology 61(8):897-910 